\title{
Alternatives to Network Selection in Heterogeneous Wireless Environments
}

\author{
Vinícius de Miranda Rios*, Claudio de Castro Monteiro**, Vanice Canuto Cunha*** \\ *Information Systems Department, University of Tocantins, Palmas - TO - Brazil \\ **Federal Institute of Education, Science and Technology of Tocantins, Computing Science Department, Palmas - TO - \\ Brazil, ACM member \\ ***University of Brasilia, Electrical Engineering Department, Brasilia - DF - Brazil \\ vinicius.mr@unitins.br,ccm.monteiro@acm.org,vanicecunha@gmail.com
}

\begin{abstract}
This article presents two proposals in order to solve the problem of choosing the best access network available in the environment where the user is located. One based on a combination of fuzzy logic technique with two decision-making methods, AHP (Analytic Hierarchy Process) and GRA (Grey Relation Analysis), and the other based only on fuzzy logic technique. In order to demonstrate the effectiveness of these proposals, they were compared with a third one, of the authors in [7], which uses a combination of AHP method with a cost function. The obtained results show that the two proposals presented in this paper are more efficient in sorting and selecting the best access network when compared to the third.
\end{abstract}

Index Terms-Network selection, AHP, GRA, Fuzzy logic

\section{INTRODUCTION}

With the emergence of wireless networks, users have become able to move into many different environments. This mobility has brought some challenges such as [1]: choosing the best access network, keeping the session to data transmission and allowing the mobile user to be always best connected anywhere and anytime on the best available access network (ABC conception - Always Best Connected).

In this sense, the next-generation wireless networks (NGWN) focus on the free users' movement between heterogeneous networks through mobile terminals (Notebooks, Netbooks, PDA - Personal Digital Assistant, cell phones, etc.) with network interfaces of different technologies (WWAN Wireless Wide Area Network, WLAN - Wireless Local Area Network, WMAN - Wireless Metropolitan Area Network, etc.) allowing continuous access to real or not real time services, always aiming at the continuity of the service (seamless).

Keeping the service active while switching access networks is the function of one of the key parts of mobility management, called handover [2]. The handover function is to control exchanges between users' access points during a data transmission [1].

Manuscript received July 30, 2012. This work was supported in part by the UnB - University of Brasilia.

Vinícius de Miranda Rios is with the UNITINS - University of Tocantins, BR Brazil (+55 (63)-3218-4926; e-mail: vinicius.mr@unitins.br).

Claudio de Castro Monteiro is with the IFTO - Federal Institute of Education, Science and Technology of Tocantins, BR Brazil (+55 (63)-32292200; e-mail: ccm.monteiro@ acm.org).

Vanice Canuto Cunha is with the IFB - Federal Institute of Education, Science and Technology of Brasilia, BR Brazil (+55 (61)-2103-2154; e-mail: vanicecunha@gmail.com).
It can be classified into two types [3]: horizontal and vertical. The horizontal handover is designed to manage switching between similar network technologies (e.g. wi-fi (Wireless Fidelity) to wi-fi) during a data transfer, in which only the signal loss is the motivation for the exchange of access points, whereas the vertical handover aims to manage switching between different access technologies (e.g. wi-fi to $3 \mathrm{G})$ during a data transmission, in which the use of preferred applications requiring certain thresholds for each requirement of QoS (Quality of Service) or the user preferences are the motivators for exchanging access points [4].

This access network exchange happens in three distinct steps, which are [2]:

- finding networks in the environment in which the mobile device is located;

- approaches to decision making/selection of the best available access network;

- the implementation of the change of the access points.

Therefore, the network selection, as an integrating and indispensable part of the handover management, aims to provide the mobile user with the best traffic condition access point, allowing applications, whether voice, data or video, to be transmitted with the required quality from source to destination.

The remainder of this paper is organized as follows: section 2 presents related work to the techniques used; section 3 describes the proposed network selection; the characterization of the experiments is shown in section 4; in section 5 , the obtained results are displayed stating which proposal is the best; and finally, section 6 presents the conclusion and future work.

\section{RELATED WORK}

The authors in [11] make a comparison among the MADM, SAW, WP and TOPSIS methods, whose goal is to classify access networks in three different scenarios. In the first scenario, TOPSIS and SAW methods proved similar in classification of networks, while the WP method showed a slight variation in its classification. In the second scenario, where two networks are removed from the classification, the SAW and WP methods proved similar, while the TOPSIS method obtained a change in its classification for suffering from the problem of abnormality ranking. Finally, a distinction between the classifications obtained in the previous scenarios is presented in the third scenario, where the TOPSIS method proves to be more consistent in the variations, while the SAW and WP methods are constant with little variability in the classification of networks. 
The network selection made by the authors in [12] is based on a fuzzy multiple criteria decision-making, where all the selected criteria are normalized by a normalization function and the result is fuzzified, generating a degree of membership between 0 and 1 , which will be used to give weights to these criteria. Finally, the selection of the best access network is made by a cost function.

The network selection algorithm of the authors in [7] is premised on originally giving preference to the UMTS (Universal Mobile Telecommunications System) in case the wi-fi is not available, since the former has a larger geographical coverage and does not allow the mobile device to run out of connection. Thus, the environment where the terminal is located is composed of four networks: three wi-fi access points and a $3 \mathrm{G}$ base station (cellular network). Therefore, the mobile terminal is shifted $1000 \mathrm{~m}$, at an average speed of $1 \mathrm{~m} / \mathrm{s}$, with $3 \mathrm{G}$ coverage during all its path, while the wi-fi network coverage is segmented.

Therefore, the mobile device only initializes the data collection in order to select the best access network when there is at least one wi-fi network available, when the signal limit is greater than the established limit and when it may possibly stay longer in this environment, avoiding the pingpong effect, thus. After confirmation, the mobile device initiates the data collection.

The final decision on network selection shall be taken by the cost function (4), in which the weights used by $W_{j}$ are given through the AHP method. In this way, the authors standardized parameters using the following assumptions:

The bigger, the better:

$$
S\left(x_{i j}\right)=\frac{x_{i j}}{\max \left\{\mathrm{x}_{\mathrm{ij}} \mid \mathrm{i}=1,2, \ldots, \mathrm{m}\right\}}
$$

The smaller, the better:

$$
S\left(x_{i j}\right)=\frac{\min \left\{\mathrm{x}_{\mathrm{ij}} \mid \mathrm{i}=1,2, \ldots, \mathrm{m}\right\}}{x_{i j}}
$$

Where $x_{i j}$ express parameter $j$ in network $i$.

The normalization of the parameters is:

$$
N\left(x_{i j}\right)=\frac{S\left(x_{i j}\right)}{\sum_{j=1}^{n} S\left(x_{i j}\right)} \quad i=1,2, \ldots, m
$$

Therefore, the rate of network decision-making can be calculated as:

$$
I_{i}=\sum_{j=1}^{n} w_{j} N\left(X_{i j}\right) \quad i=1,2, \ldots, m
$$

The values of each parameter used to select the best access network are characterized in Table I.

TABLE I.

NETWORK PARAMETERS

\begin{tabular}{|l|c|c|c|c|c|}
\hline \multicolumn{2}{|c|}{ Parameters } & UMTS & WLAN1 & WLAN2 & WLAN3 \\
\hline QoS & Available & 0,4 & 20 & 10 & 30 \\
\hline
\end{tabular}

\begin{tabular}{|l|l|c|c|c|c|}
\hline \multirow{2}{*}{ factors } & bandwidth & & & & \\
\cline { 2 - 6 } & Delay & 20 & 30 & 50 & 40 \\
\cline { 2 - 6 } & Jitter & 5 & 10 & 10 & 10 \\
\hline Cost & $\begin{array}{l}\text { Bit error } \\
\text { rate }\end{array}$ & $10^{-9}$ & $10^{-6}$ & $10^{-6}$ & $10^{-5}$ \\
\hline \multirow{2}{*}{ Reliability } & $\begin{array}{l}\text { Packet } \\
\text { Loss }\end{array}$ & 0,01 & 0,1 & 0,2 & 0,1 \\
\hline & Cell load & 0,3 & 0,8 & 0,1 & 0,8 \\
\hline Securit & & 8 & 4 & 2 & 4 \\
\hline
\end{tabular}

The entire article was implemented by using the EXCEL spreadsheet. There the data provided by the authors were inserted, as well as the values of the collected parameters and also the implementation of the AHP method and the above equations, which reached the same values of weights and results presented in the article.

The exception of results could be noticed in the normalization of parameters of the scenario when the mobile is in the area of WLAN2, WLAN3 and 3G network coverage. The parameters $\alpha, \beta, \gamma$ and $\delta$, express the QoS factors, cost, reliability and security respectively. The values generated by our implementation differ from those provided by the article, as shown in tables II and III below.

TABLE II.

NORMALIZATION OF NETWORK PARAMETERS

\begin{tabular}{|l|c|c|c|c|c|c|c|c|}
\hline $\begin{array}{c}\text { Simulation } \\
\text { Scenarios }\end{array}$ & \multicolumn{3}{|c|}{$\boldsymbol{\alpha}$} & \multicolumn{3}{|c|}{$\boldsymbol{\beta}$} & \multicolumn{3}{|c|}{$\gamma$} & $\boldsymbol{\gamma}$ \\
\hline UMTS & 0.01 & 0.48 & 0.50 & 0 & 1 & 0.87 & 0.23 & 0.57 \\
\hline WLAN2 & 0.33 & 0.32 & 0.25 & 0.50 & 0 & 0.09 & 0.09 & 0.29 \\
\hline WLAN3 & 0.66 & 0.20 & 0.25 & 0.50 & 0 & 0.04 & 0.68 & 0.14 \\
\hline
\end{tabular}

TABLE III.

OUR NORMALIZATION OF NETWORK PARAMETERS

\begin{tabular}{|l|c|c|c|c|c|c|c|c|}
\hline $\begin{array}{c}\text { Simulation } \\
\text { Scenarios }\end{array}$ & \multicolumn{3}{|c|}{$\boldsymbol{\alpha}$} & $\boldsymbol{\beta}$ & \multicolumn{3}{|c|}{$\gamma$} & $\boldsymbol{\delta}$ \\
\hline UMTS & 0.01 & 0.53 & 0.50 & 0 & 1 & 0.87 & 0.23 & 0.57 \\
\hline WLAN2 & 0.25 & 0.21 & 0.25 & 0.50 & 0 & 0.04 & 0.69 & 0.14 \\
\hline WLAN3 & 0.99 & 0.33 & 0.33 & 0.99 & 0 & 0.09 & 0.27 & 0.33 \\
\hline
\end{tabular}

A big difference between the values generated by the normalization equation (3) of the authors in [7] in Table II can be observed in relation to our values presented in Table III. Therefore, the result we reached was that, in the scenario where the preference is for reliability and security, the mobile selected the $3 \mathrm{G}$ network all the times, whereas in the article there is a selection for WLAN2 network.

In addition, when we implement the article in a real testbed, we can observe that if there is a value of the collected parameters equal to 0 , its final result will also be 0 , thus affecting the choice of the best access network, as it is shown in section 5 .

\section{PROPOSALS}

The proposals of this work are presented here with the intention of using the fuzzy logic, AHP and GRA for the composition of an architecture of network selection in heterogeneous wireless network environments. 


\section{A. Proposal 1- Network selection by using Fuzzy logic}

The first network selection proposal aims to using only the technique of fuzzy logic considering the accurate output provided upon the input of raw data collected by the system, as it is illustrated in Figure 1.

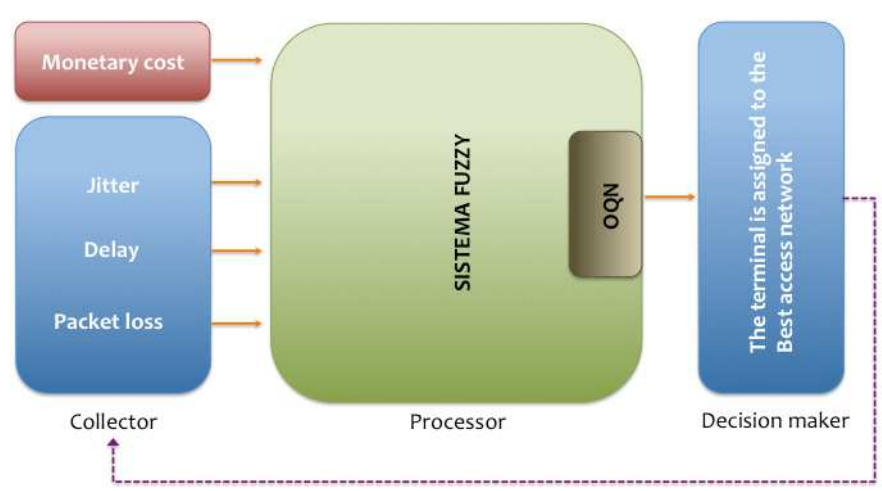

Figure 1. Architecture of proposal 1 using only fuzzy logic only.

Thus, the system is divided into three functional blocks, which are: the collector, processor and decision-maker.

\section{Collector}

The collector aims to collecting data on delay, jitter and packet loss, provided by the ping application, as it can be seen in Figure 2. The monetary cost parameter is fixed, so there is no need to be collected, but only informed by the mobile operator, taking the value of wi-fi networks equal to zero real and the values in networks 1 and 2 base stations equal to 89.9 and 79.9 brazilian reals, respectively, since only the access from the terminal to the access point is considered, i.e., the ICMP (Internet Control Message Protocol) requisitions of the ping (packet internet grouper) application will be transmitted from the client terminal to the interface output gateway, passing only by the access point it is connected.

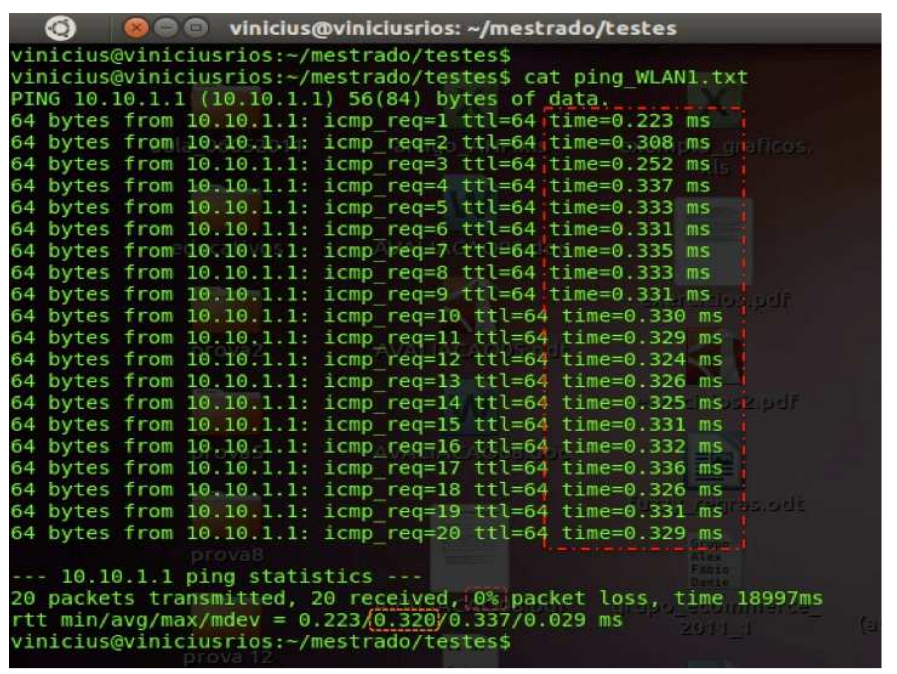

Figure 2. File with the collection of ICMP requisitions.
This collection takes place through two rounds of 10 ICMP requisitions, and because we are dealing with the sum of all end-to-end delay [8], the average RTT (Round Trip Time) values are also stored in each round.

TABLE IV.

PSEUDOCODE FOR COLLECTOR FUNCTION

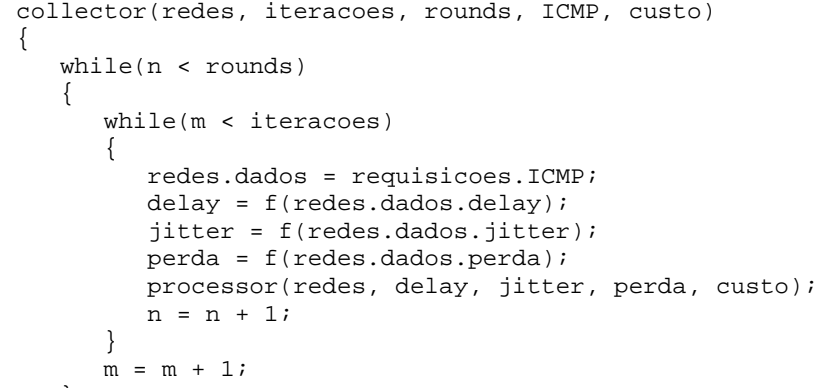

\section{Processor}

The processor aims to manipulate the data that is collected through the fuzzy logic technique in order to classify access networks in the environment the terminal is located. For this, audio thresholds were used in the fuzzy system, because they are already well known and documented and they also state that in an audio transmission (VoIP), the delay cannot be greater than $300 \mathrm{~ms}$, the jitter cannot be greater than $150 \mathrm{~ms}$ and the packet loss may not exceed over 3\% [9], [10], which makes the sound unintelligible to the human ear in such cases.

Under this assumption, each linguistic variable (jitter, delay, packet loss and monetary cost) has three linguistic terms in the fuzzy system, which are: low, medium and high, where the universe of discourse of each of them is within the thresholds of the audio traffic. Each of these terms was fuzzified with the function of triangular relevance and in accordance with the Mandani method inference on the obtained result, as it can be seen in Figure 3.
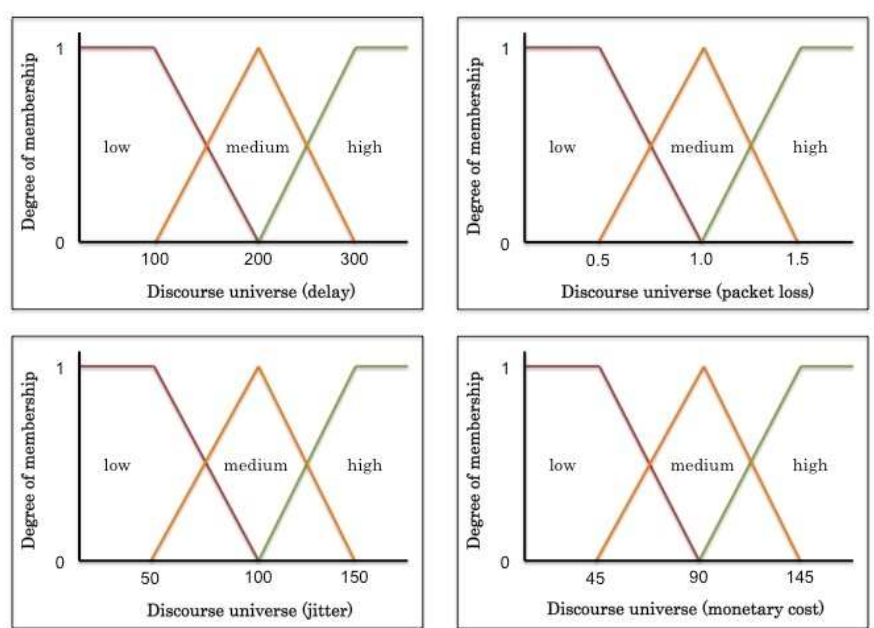

Figure 3. Fuzzification.

Each fuzzy subset within the discourse universe associated with the delay is composed of: 
- low, between 0 and 200;

- medium, between 100 and 300;

- high, above 300.

But the discourse universe associated with the jitter is composed of:

- low, between 0 and 100 ;

- medium, between 50 and150;

- high, above 150.

The same happens in the discourse universe associated with the packet loss:

- low, between 0 and 1 ;

- medium, between 0.5 and 1.5 ;

- high, above 1.5 .

And finally, the discourse universe associated with the monetary cost:

- low, between 0 and 90;

- medium, between 45 and 145;

- high, above 145 .

Figure 4 illustrates the rules used in this proposal.

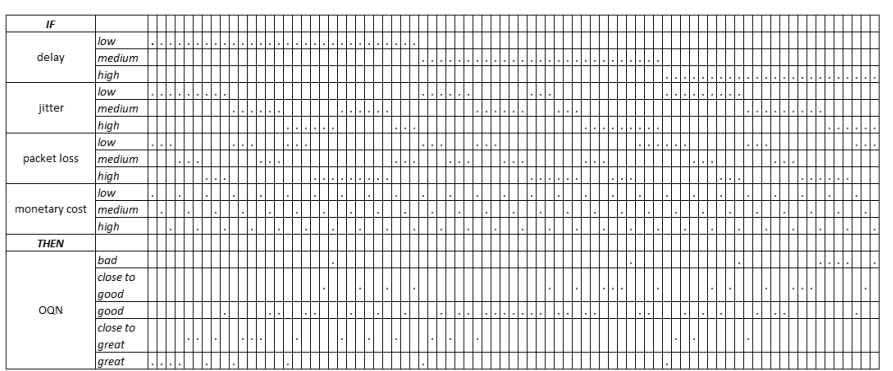

Figure 4. Rule Base.

Finally, in the fuzzification, there is the linguistic variable called OQN (Objective Quality of Network) which has five linguistic terms: bad, close to good, good, close to great and great, as it can be seen in Figure 5. The final result is calculated by the center of maximum defuzzification method.

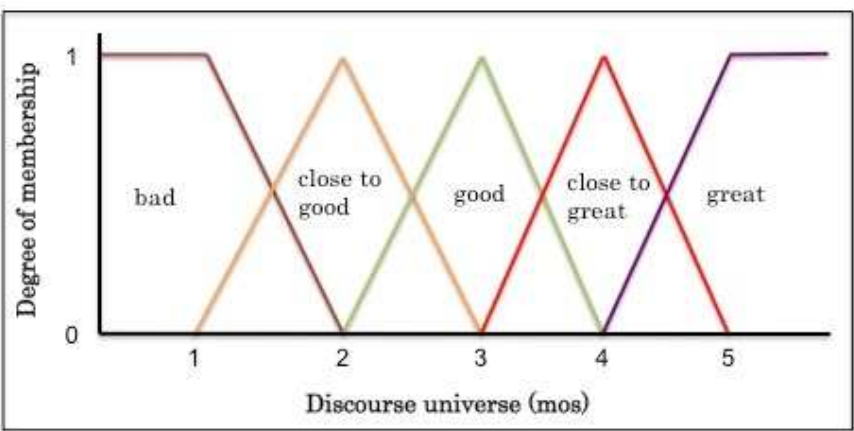

Figure 5. Defuzzification.

Each fuzzy subset within the discourse universe associated with OQN is composed of:

- bad, between 0 and 1 ;

- close to good, between 1 and 3;

- good, between 2 and 4;

- close to great, between 3 and 5;

- great, above 5 .

TABLE V.

PSEUDOCODE FOR PROCESSOR FUNCTION

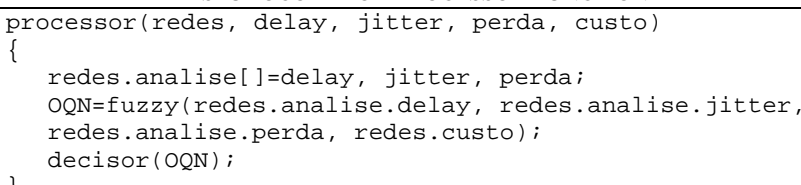

\section{Decision-Maker}

The decision-maker module checks, every 60 seconds, the total time of iteration, the highest score access point generated by the processor module, then stores it in a text file, thereby allowing any mobility management solution on layer 3 to read it and to take the decision to perform the handover to the network stored in its content. Then, as it can be seen, the proposed fuzzy system consists of four inputs and one output, the latter stating how much quality each network has using the OQN variable.

TABLE VI.

PSEUDOCODE FOR DECISION FUNCTION

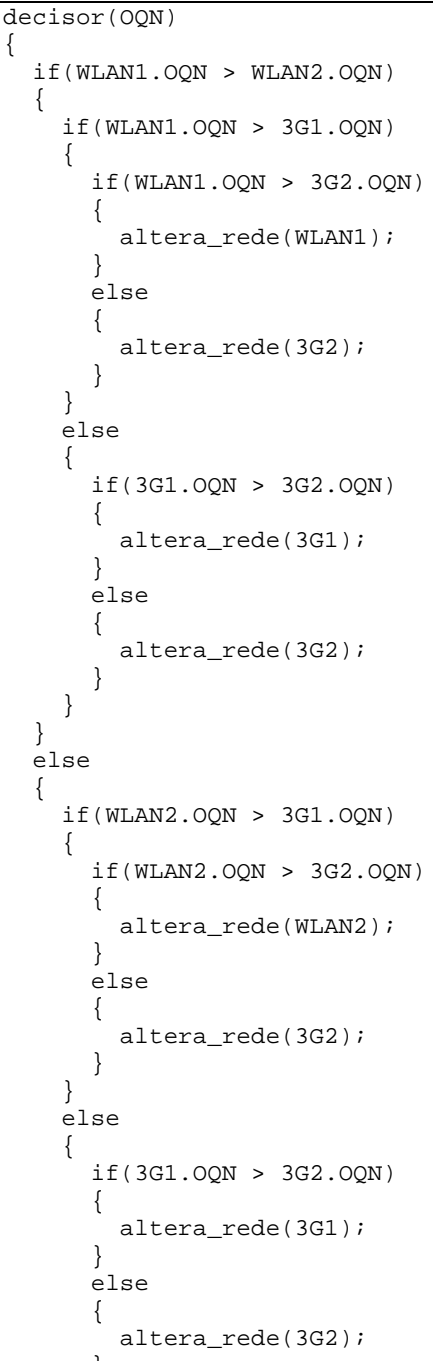




\section{Main}

The algorithm is modularized and parameterized, i.e., it enables the user to perform the experiments with the necessary amount of ICMP repetitions and requisitions. The algorithm below is started to pass on the information the collector module will need to gather the values to be processed by the processor module.

TABLE VII

PSEUDOCODE FOR MAIN FUNCTION

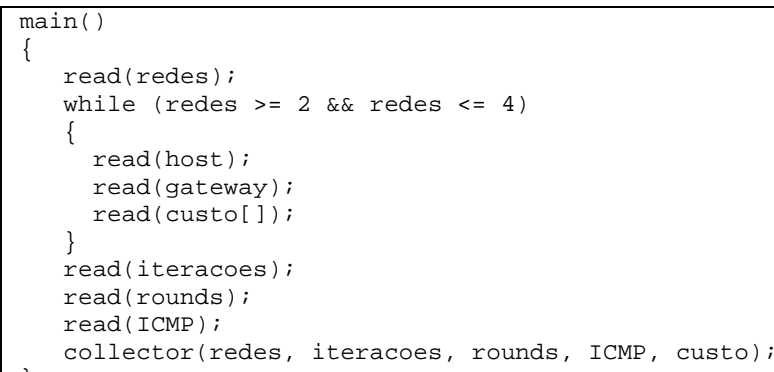

\section{B. Proposal 2 - Network Selection using Fuzzy Logic, AHP and GRA}

The aim of the second proposal of network selection is to use the combination of two strategies: fuzzy logic, which is alike the first proposal, combined with two MADM methods, AHP and GRA. This combination aims to propose a different vision of combination between decision-making methods and artificial intelligence techniques.

The choice of AHP was motivated by being an efficient method to generate weights for objective data, while the choice of GRA was motivated by being a very efficient method in sorting alternatives to meet a particular purpose, in this case, the choice of the best access network, as it can be noted in the authors' article [4], and [11]. Figure 6 illustrates this proposal.

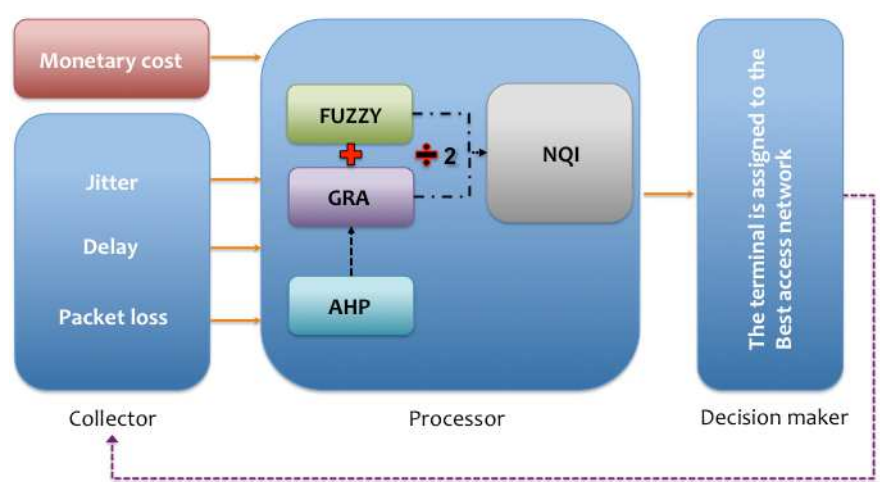

Figure 6. Architecture of Proposal 2 using fuzzy logic, AHP and GRA.

Just as in proposal 1, the system is divided into three functional blocks, which are: the collector, the processor and the decision-maker.

\section{Collector}

The collector module works the same way as in the first proposal.

\section{Processor}

The processor module uses all the features of the fuzzy logic of the first proposal and, in parallel, it uses the GRA method, which will also receive the same collected values of jitter, delay, packet loss and monetary cost. The generated result will be the rank (score) of each network. This classification is possible due to the weights provided by the AHP, according to each criterion. The weights generated by the AHP for jitter, delay, packet loss and monetary cost criteria are $0.18,0.25,0.05$ and 0.52 , respectively.

These weight values were based on the importance of each QoS criterion of network for audio transmission, i.e., for voice traffic the jitter has a bit greater importance than the delay and they have far greater importance than the packet loss [10], while the monetary cost to the user's preference has much greater importance than the previous criteria, since it is assumed that the user will always opt for the cheapest access network when a change in the access network is necessary.

TABLE VIII.

PSEUDOCODE FOR PROCESSOR FUNCTION

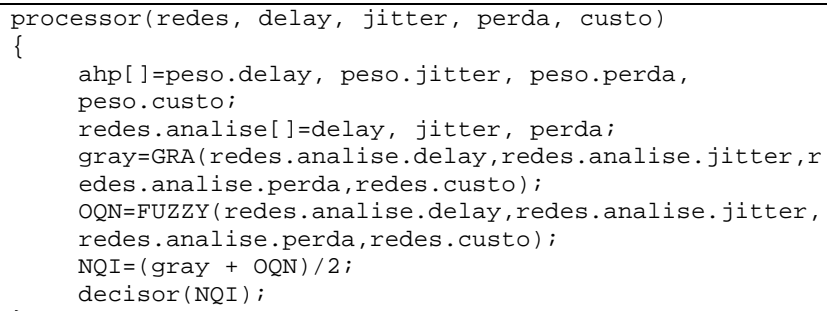

The decision-maker module checks, every 60 seconds, the total time of iteration, the highest score access point generated by the processor module, then stores it in a text file, thereby allowing any software to read it and to take the decision to perform the handover to the network stored in its content. Then, as it can be seen, the proposed fuzzy system consists of four inputs and one output. This output informs how much quality each network has using the NQI (Network Quality Index) variable. The value of this variable is the result of the arithmetic average of the OQN variable value with the GRA value.

TABLE IX.

PSEUDOCODE FOR DECISION FUNCTION

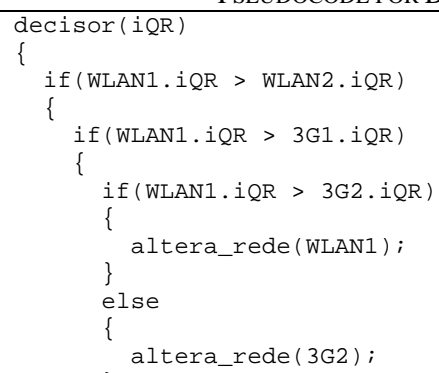




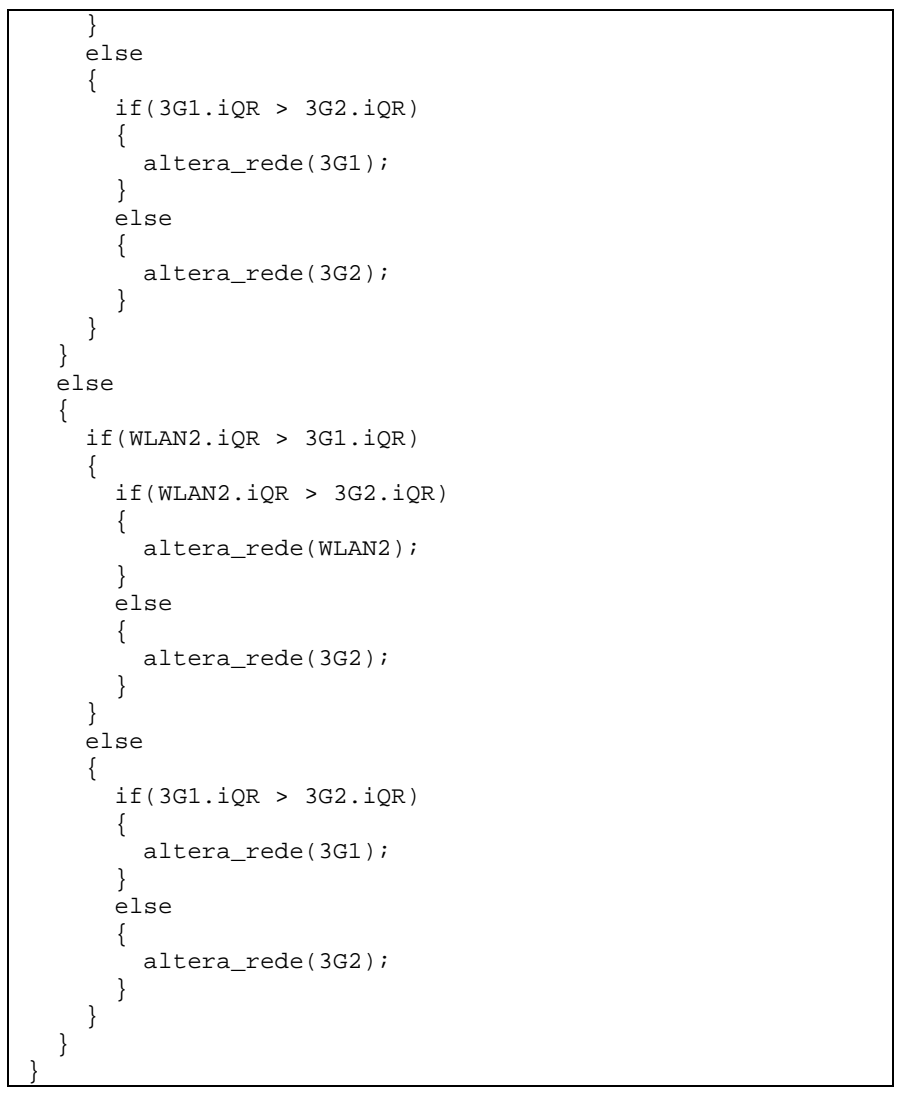

Main

The algorithm is modularized and parameterized, i.e., it enables the user to perform the experiments with the necessary amount of ICMP repetitions and requisitions. The algorithm below is started to pass on the information the collector module will need in order to gather the values to be processed by the processor module.

TABLE X.

PSEUDOCODE FOR MAIN FUNCTION

\begin{tabular}{|l} 
main () \\
$\quad$ read(redes); \\
$\quad$ while(redes <= 2) \\
$\quad\{\quad$ read(host); \\
$\quad \quad$ read(gateway); \\
$\quad$ read(custo); \\
$\quad$ read(iteracoes); \\
$\quad$ read(rounds); \\
$\quad$ read(ICMP); \\
collector(redes, iteracoes, rounds, ICMP);
\end{tabular}

\section{METHODOLOGY}

Here the necessary procedures to implement the proposals outlined above are presented in order to demonstrate the effectiveness in the proposed scenarios.

\section{Experiments without mobility}

To assess the impact of network parameters (QoS), jitter, delay and packet loss, besides the monetary cost parameter in the network selection process without mobility, a scenario involving two computers and two wi-fi access points was set up, structured as shown in Figure 7 and with the following function:

- Computer 1: Client;

- Computer 2: Router;

- wi-fi access point 1: 802.11b;

- wi-fi access point 2: 802.11g;

- 3G Base Station 1: UMTS;

- 3G Base station 2: UMTS.

The client computer has two USB (Universal Serial Bus) network interfaces and two USB 3G network interfaces, each previously connected to its respective access point. Therefore, the wi-fi interfaces are connected to access points 1 and 2, while the $3 \mathrm{G}$ interfaces are connected to base stations 1 and 2 of distinct cellular operators.

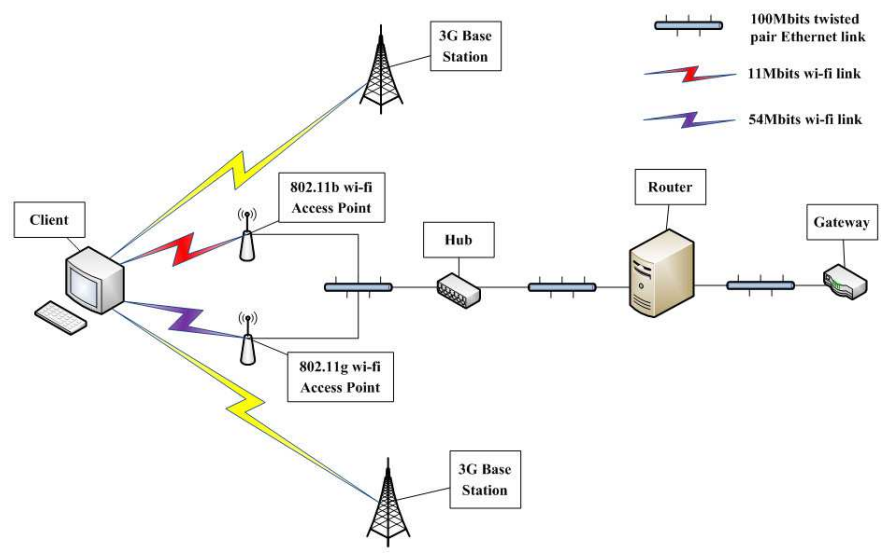

Figure 7. Representation of the scenario structure of the tests without mobility.

All computers used in the assembly of this scenario have the same configuration: Intel Atom Dual Core processor, 2GB RAM and 500GB hard drive. Table 10 shows the list of software and hardware installed and used on the computers.

TABLE XI.

LIST OF SOFTWARE AND HARDWARE USED IN THE SCENARIO FOR THE EXPERIMENTS

\begin{tabular}{|l|l|l|}
\hline Computer & Software & Hardware \\
\hline 1 & - Linux Ubuntu v. & - Two wi-fi network cards: \\
& 11.04 Natty Narwhal & $*$ Tenda 802.11N pattern. \\
& Operating System; & - Two 3G network cards: \\
& & $*$ ONDA MAS190UP model; \\
& - gcc v. 4.5.2 & $*$ HUAWEI E173 model. \\
\hline 2 & - FreeBSD v. 8.2 & - Three network cards: \\
& operating system. & $* 100$ Mbits Ethernet. \\
& & \\
& - ipfw dummynet v. 4. & \\
\hline
\end{tabular}

Thus, the experiment consisted of 35 iterations. Each iteration is composed of two rounds and each turn consists of 10 ICMP requisitions from the client bound to the network gateway where the interface is connected. The values of jitter, delay and packet loss generated in these two turns were collected during a whole week, in the morning, afternoon and 
evening, totaling 420 iterations on a single day. Each item of this experiment has the following characteristics:

- iteration: includes the whole process, i.e., collection, processing and decision;

- turn: is the action of collecting the data for each network criterion;

- collection: consists of sending ICMP requisitions to the gateways of each network interface;

- collection time: is the time at which the collection is performed.

It is noteworthy that the best access network is selected in each iteration (60 seconds). The competing traffic generated by the server through ipfw (ipfirewall) command was only for wi-fi networks, since telecommunication operators do not allow access to the infrastructure core of $3 \mathrm{G}$ networks.

\section{Experiments with mobility}

To assess the impacts of network parameters (QoS), jitter, delay and packet loss, in addition to the monetary cost parameter in the network selection process with mobility, a scenario with a notebook, access point and a $3 \mathrm{G}$ operator was set up, structured as shown in Figure 8 and having the following function:

- notebook;

- wi-fi access point: $802.11 \mathrm{~g}$ pattern;

- 3G Base station: UMTS.

The client computer contains a wi-fi network interface and a USB $3 \mathrm{G}$ network interface, which are previously connected, each to its respective access point. The wi-fi interface is connected to the access point, while the $3 \mathrm{G}$ interface is connected to a base station of a mobile operator.

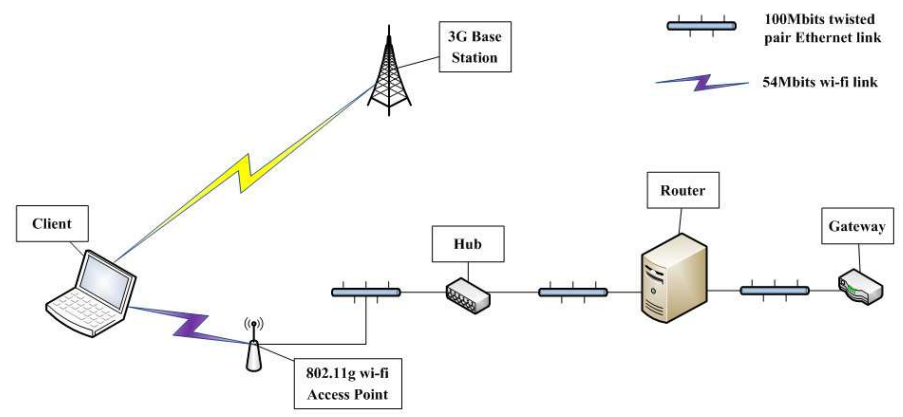

Figure 8. Representation of the structure of the test scenario with mobility.

The notebook used in this scenario has the following configuration: Intel Core 2 Duo $2.4 \mathrm{Ghz}$ processor, 4GB RAM and 250GB hard drive. Table 16 shows the list of installed and used software and hardware.

TABLE XII.

LIST OF SOFTWARE AND HARDWARE USED IN THE SCENARIO FOR THE EXPERIMENTS

\begin{tabular}{|l|l|l|}
\hline Computer & Software & Hardware \\
\hline 1 & - Linux Ubuntu v. 11.04 & - One wi-fi network card: \\
& Natty Narwhal & $*$ Broadcom model \\
& Operating System; & BCM4328 802.11b/g pattern. \\
& & - One 3G network card: \\
& - gcc v. 4.5.2. & * ONDA MAS190UP model; \\
\hline
\end{tabular}

Thus, the experiments consisted of 358 iterations generated during the one hundred (100) drives, in which fifty (50) from the starting point toward the edge of the wi-fi access point cell and fifty (50) from the edge of the wi-fi access point cell to the starting point, at an average speed of $1 \mathrm{~m} / \mathrm{s}$ straight, as it can be seen in Figure 9.

Each iteration is composed of two turns and each turn consists of 10 ICMP requisitions from the client bound only to the gateway of each one of the access networks. It collects the values of jitter, delay and packet loss generated in these two turns. It is important to stress that the best access network is selected in each iteration (60 seconds). Each item of this experiment has the following characteristics:

- iteration: includes the whole process, i.e., collection, processing and decision;

- turn: is the action of collecting the data for each network criterion;

- collection: consists of sending ICMP requisitions to the gateways of each network interface.

- collection time: is the time at which the collection is performed.

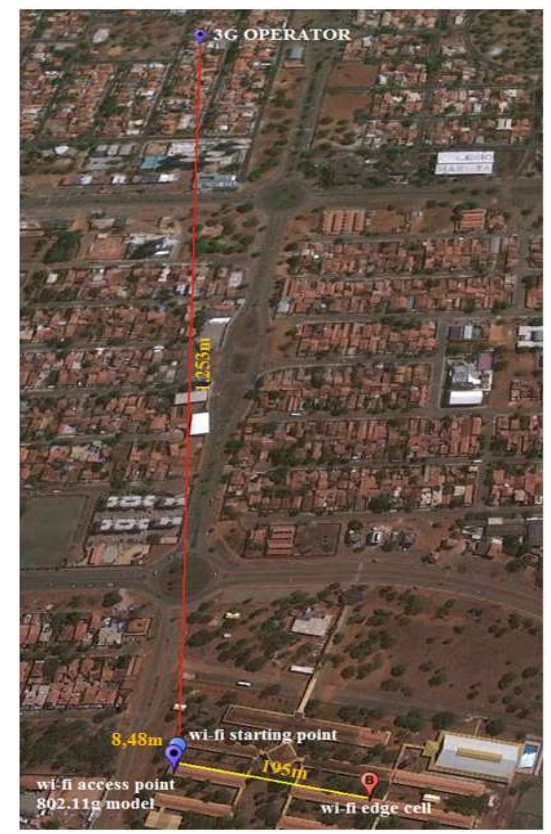

Figure 9. Trajectory of the mobile.

Based on the experiments of these two scenarios, some analyses were necessary to validate the proposals presented in this article.

\section{RESUltS}

\section{E. Results of the experiments without mobility}

The result obtained with each of the proposals in the scenario without mobility is characterized in the following figures, in which charts 1,2 and 3 represent the collector and the processor modules, while charts 4,5 and 6 represent the decision-maker module. In each examination, a universe of 420 collection iterations of network variables (delay, jitter and 
packet loss) was observed and also the amount of times a particular network was selected by each of the proposals. This amount is expressed in percentage in charts 4 to 6 , while in charts $1(\mathrm{P} 1), 2(\mathrm{P} 2)$ and $3(\mathrm{P} 3)$ the averages of these selected network variables are shown considering the set of samples which resulted in the selection of that particular network. This methodology was followed for the presentation of other results.

\section{No competing traffic on WLAN1 and WLAN2 networks}

Figure 10 shows that proposals 2 and 3, charts 5 and 6 respectively, have succeeded in obtaining great performance in selecting the best access network, within the given characteristics.

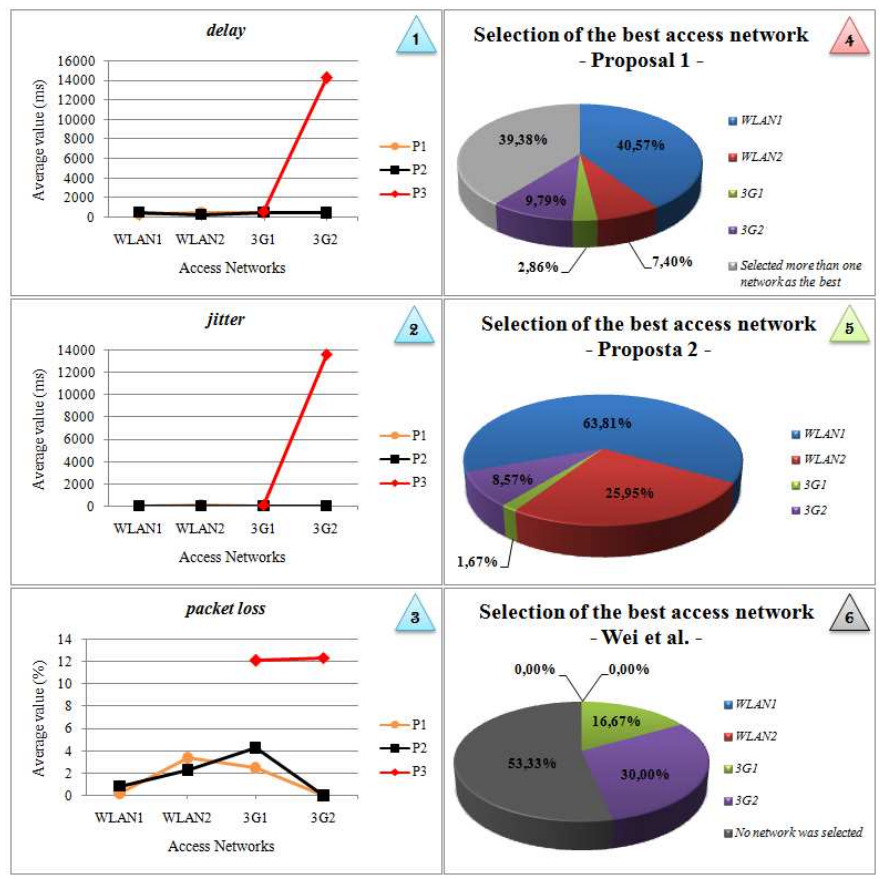

Figure 10. No competing traffic on the WLAN1 and WLAN2 networks.

As it can be seen in chart 5, WLAN1 network has got $63.81 \%$ of choice, averaging its delay network parameter around $500 \mathrm{~ms}$, jitter around $30 \mathrm{~ms}$ and packet loss around $1 \%$. The WLAN2 network has obtained $25.95 \%$ of choice, averaging its delay network parameter around $300 \mathrm{~ms}$, jitter around $60 \mathrm{~ms}$ and packet loss around $2 \%$. The 3G1 network has obtained $1.67 \%$ of choice, averaging its delay network parameter around $500 \mathrm{~ms}$, jitter around $60 \mathrm{~ms}$ and packet loss around $4 \%$. And finally, the 3G2 network has obtained $8.57 \%$ of choice, averaging its delay network parameter around $450 \mathrm{~ms}$, jitter around $60 \mathrm{~ms}$ and packet loss around $0 \%$.

In the first proposal, represented by the fourth chart, there is $39.38 \%$ of choice in the selection of more than one access network, which is a problem, since the handover has to happen for the best network selected. The WLAN1 network has got $40.57 \%$ of choice, averaging its delay network parameter around $350 \mathrm{~ms}$, jitter around $50 \mathrm{~ms}$ and packet loss around $0 \%$. The WLAN2 network has obtained $7.40 \%$ of choice, averaging its delay network parameter around $500 \mathrm{~ms}$, jitter around $150 \mathrm{~ms}$ and packet loss around 3\%. The 3G1 network has obtained $2.86 \%$ of choice, averaging its delay network parameter around $450 \mathrm{~ms}$, jitter around $60 \mathrm{~ms}$ and packet loss around 3\%. Finally, the 3G2 network has got $9.79 \%$ of choice, averaging its delay network parameter around $550 \mathrm{~ms}$, jitter around $60 \mathrm{~ms}$ and packet loss around $0 \%$.

The authors' proposal in [7], represented by chart 6 , has not selected any network in $53.33 \%$ of total iterations, because in addition to the criterion of packet loss that can have a value of 0 , the monetary cost criterion has a value of 0 real in the WLAN1 and WLAN2 networks. The 3G1 network has obtained $16.67 \%$ of choice, averaging its delay network parameter around $600 \mathrm{~ms}$, jitter around $180 \mathrm{~ms}$ and packet loss around $12 \%$. The $3 \mathrm{G} 2$ network has got $30 \%$ of choice, averaging its delay network parameter around $14000 \mathrm{~ms}$, jitter around $13500 \mathrm{~ms}$ and packet loss around $13 \%$.

\section{Moderate competing traffic in the WLAN1 network}

Figure 11 shows that proposals 2 and 3, charts 5 and 6 respectively, have succeeded in obtaining great performance in selecting the best access network, within the given characteristics.

As it can be seen in chart 5, the WLAN2 network obtained $61.19 \%$ of choice, averaging its delay network parameter around $400 \mathrm{~ms}$, jitter around $60 \mathrm{~ms}$ and packet loss around $1 \%$. The 3G1 network has obtained $9.29 \%$ of choice, averaging its delay network parameter around $400 \mathrm{~ms}$, jitter around $70 \mathrm{~ms}$ and packet loss around 0\%. And finally, the 3G2 network has obtained $29.52 \%$ of choice, averaging its delay network parameter around $400 \mathrm{~ms}$, jitter around $60 \mathrm{~ms}$ and packet loss around $0 \%$. It may be observed that because the WLAN1 network parameters are above the audio traffic parameters considered as good or great, it was not selected in any of the iterations.

In the first proposal, represented by chart 4 , there is $0.24 \%$ of choice in selecting more than one access network, which causes a problem, since the handover has to happen for the best network selected. The WLAN2 network has obtained $55.24 \%$ of choice, averaging its delay network parameter around $400 \mathrm{~ms}$, jitter around $60 \mathrm{~ms}$ and packet loss around $1 \%$. The 3G1 network has obtained $11.19 \%$ of choice, averaging its delay network parameter around $400 \mathrm{~ms}$, jitter around $70 \mathrm{~ms}$ and packet loss around $0 \%$. And finally, the $3 \mathrm{G} 2$ network has obtained $33.33 \%$ of choice, averaging its delay network parameter around $400 \mathrm{~ms}$, jitter around $60 \mathrm{~ms}$ and packet loss around $0 \%$.

The authors' proposal in [7], represented by chart 6 , has not selected any network in $75.95 \%$ of total iterations, because in addition to the criterion of packet loss that can have a value of 0 , the monetary cost criterion has a value of 0 real in the WLAN1 and WLAN2 networks. The 3G1 network has obtained $6.19 \%$ of choice, averaging its delay network parameter around $700 \mathrm{~ms}$, jitter around $300 \mathrm{~ms}$ and packet loss around $8 \%$. The $3 \mathrm{G} 2$ network has obtained $17.86 \%$ of choice, averaging its delay network parameter around $4800 \mathrm{~ms}$, jitter around $4100 \mathrm{~ms}$ and packet loss around $3 \%$. 


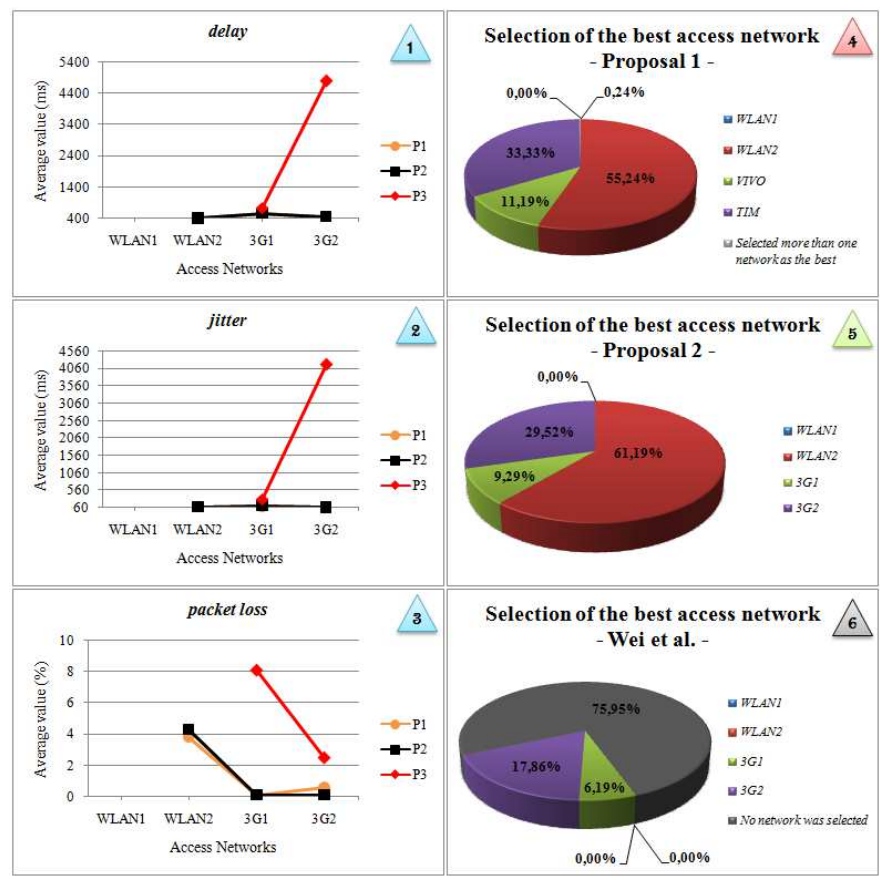

Figure 11. Moderate competing traffic in the WLAN1 network.

Moderate competing traffic in the WLANI network

Figure 12 shows that proposals 2 and 3, charts 5 and 6 respectively, have succeeded in obtaining great performance in selecting the best access network, within the given characteristics.

As it can be seen in chart 5, the WLAN1 network has got $82.62 \%$ of choice, averaging its delay network parameter around $300 \mathrm{~ms}$, jitter around $20 \mathrm{~ms}$ and packet loss around $2 \%$. The $3 \mathrm{G} 1$ network has obtained $2.86 \%$ of choice, averaging its delay network parameter around $400 \mathrm{~ms}$, jitter around $120 \mathrm{~ms}$ and packet loss around $0 \%$. And finally, the 3G2 network has obtained $14.52 \%$ of choice, averaging its delay network parameter around $400 \mathrm{~ms}$, jitter around $110 \mathrm{~ms}$ and packet loss around $2 \%$. It may be observed that because the WLAN2 network parameters are above the audio traffic parameters considered as good or great, it was not selected in any of the iterations.

In the first proposal, represented by chart 4 , there is $0.71 \%$ of choice in the selection of more than one access network, which causes a problem, since the handover has to happen for the best network selected. The WLAN1 network has got $79.52 \%$ of choice, averaging its delay network parameter around $300 \mathrm{~ms}$, jitter around $20 \mathrm{~ms}$ and packet loss around $2 \%$. The 3G1 network has obtained $3.10 \%$ of choice, averaging its delay network parameter around $400 \mathrm{~ms}$, jitter around $120 \mathrm{~ms}$ and packet loss around $0 \%$. And finally, the $3 \mathrm{G} 2$ network has obtained $16.67 \%$ of choice, averaging its delay network parameter around $400 \mathrm{~ms}$, jitter around $110 \mathrm{~ms}$ and packet loss around $2 \%$.

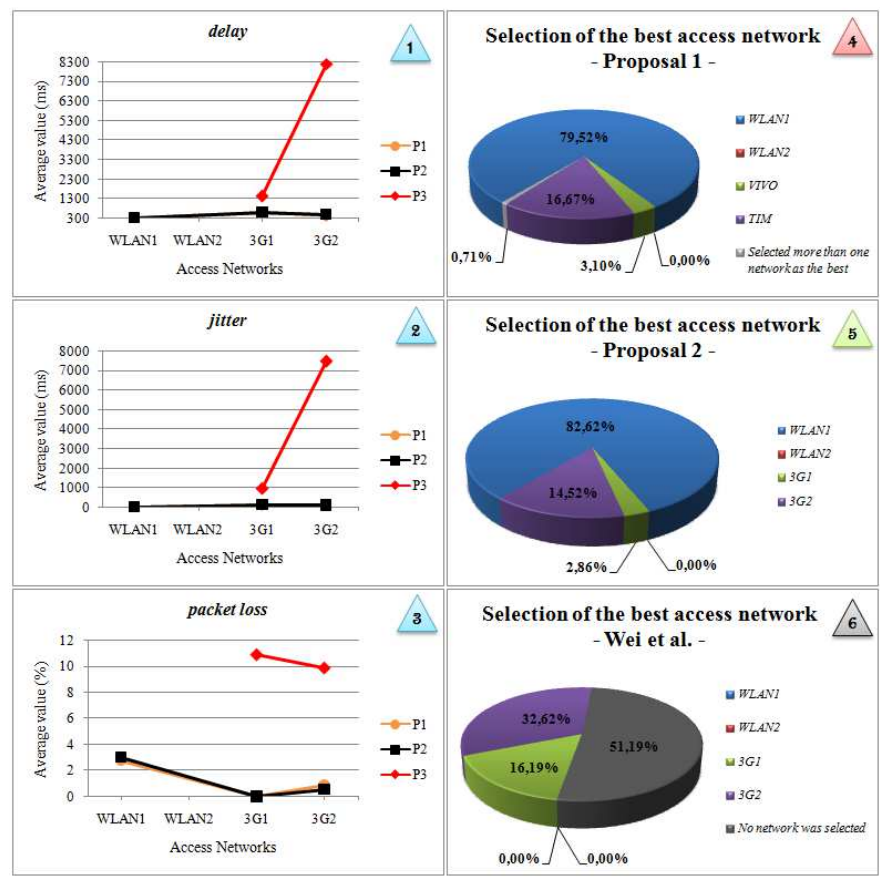

Figure 12. Moderate competing traffic in WLAN2 network.

The authors' proposal in [7], represented by chart 6 , has not selected any network in $51.19 \%$ of total iterations, because in addition to the criterion of packet loss that can have a value of 0 , the monetary cost criterion has a value of 0 real in the WLAN1 and WLAN2 networks. The 3G1 network has obtained $16.19 \%$ of choice, averaging its delay network parameter around $1400 \mathrm{~ms}$, jitter around $900 \mathrm{~ms}$ and packet loss around $10 \%$. The $3 \mathrm{G} 2$ network has obtained $32.62 \%$ of choice, averaging its delay network parameter around $8000 \mathrm{~ms}$, jitter around $7500 \mathrm{~ms}$ and packet loss around $9 \%$.

\section{Moderate competing traffic in the WLAN1 and WLAN2 networks}

Figure 13 shows that proposals 2 and 3, charts 5 and 6 respectively, have succeeded in obtaining great performance in selecting the best access network, within the given characteristics.

As it can be seen in chart 5, the $3 \mathrm{G} 1$ network has obtained $29.52 \%$ of choice, averaging its delay network parameter around $500 \mathrm{~ms}$, jitter around $60 \mathrm{~ms}$ and packet loss around $0 \%$. And finally, the 3G2 network has obtained $70.48 \%$ of choice, averaging its delay network parameter around $400 \mathrm{~ms}$, jitter around $50 \mathrm{~ms}$ and packet loss around $2 \%$. It may be observed that because the WLAN1 and WLAN2 network parameters are above the audio traffic parameters considered as good or great, they were not selected in any of the iterations. 


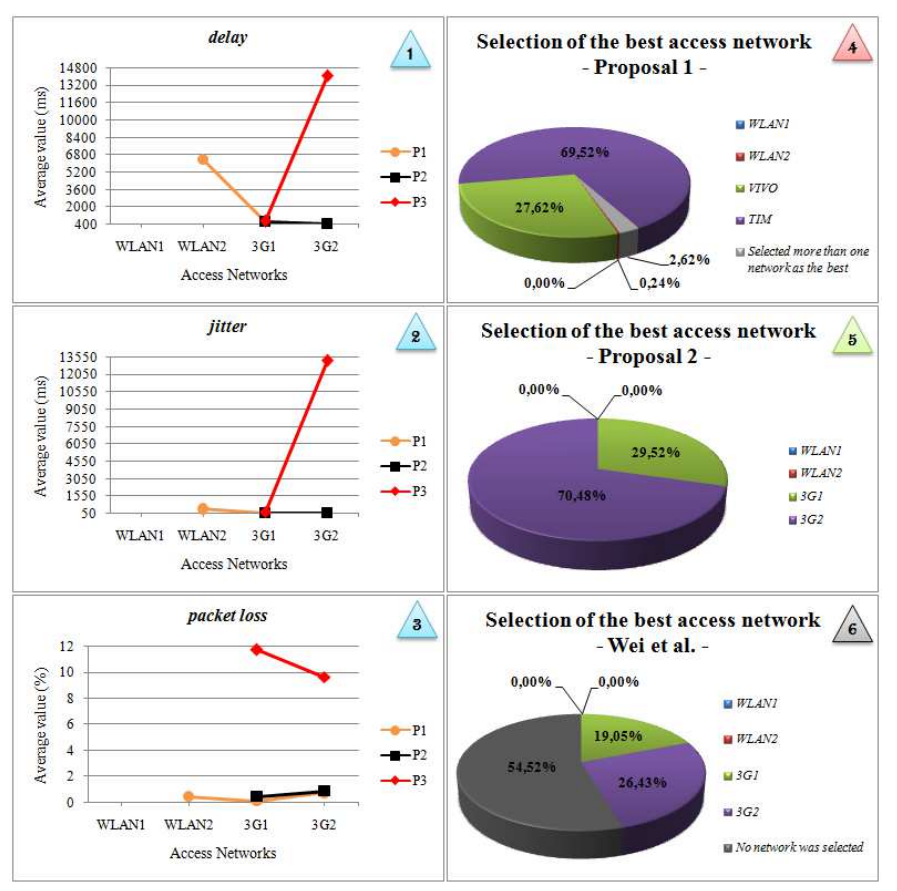

Figure 13. Moderate competing traffic in the WLAN1 and WLAN2 networks.

In the first proposal, represented by chart 4 , there is $2.62 \%$ of choice in selecting more than one access network, which is considered a problem, since the handover has to happen for the best network selected. The WLAN2 network has obtained $0.24 \%$ of choice, averaging its delay network parameter around $6700 \mathrm{~ms}$, jitter around $500 \mathrm{~ms}$ and packet loss around $0 \%$. The 3G1 network has obtained $27.62 \%$ of choice, averaging its delay network parameter around $500 \mathrm{~ms}$, jitter around $60 \mathrm{~ms}$ and packet loss around $0 \%$. And finally, the $3 \mathrm{G} 2$ network has obtained $69.52 \%$ of choice, averaging its delay network parameter around $400 \mathrm{~ms}$, jitter around $50 \mathrm{~ms}$ and packet loss around $2 \%$.

The authors' proposal in [7], represented by chart 6, has not selected any network in $54.52 \%$ of total iterations, because in addition to the criterion of packet loss that can have a value of 0 , the monetary cost criterion has a value of 0 real in the WLAN1 and WLAN2 networks. The 3G1 network has obtained $19.05 \%$ of choice, averaging its delay network parameter around $700 \mathrm{~ms}$, jitter around $200 \mathrm{~ms}$ and packet loss around $11 \%$. The $3 \mathrm{G} 2$ network has obtained $26.43 \%$ of choice, averaging its delay network parameter around $14000 \mathrm{~ms}$, jitter around $13000 \mathrm{~ms}$ and packet loss around $9 \%$.

\section{High competing traffic in the WLAN1 network}

Figure 14 shows that proposals 2 and 3, charts 5 and 6 respectively, have succeeded in obtaining great performance in selecting the best access network, within the given characteristics.

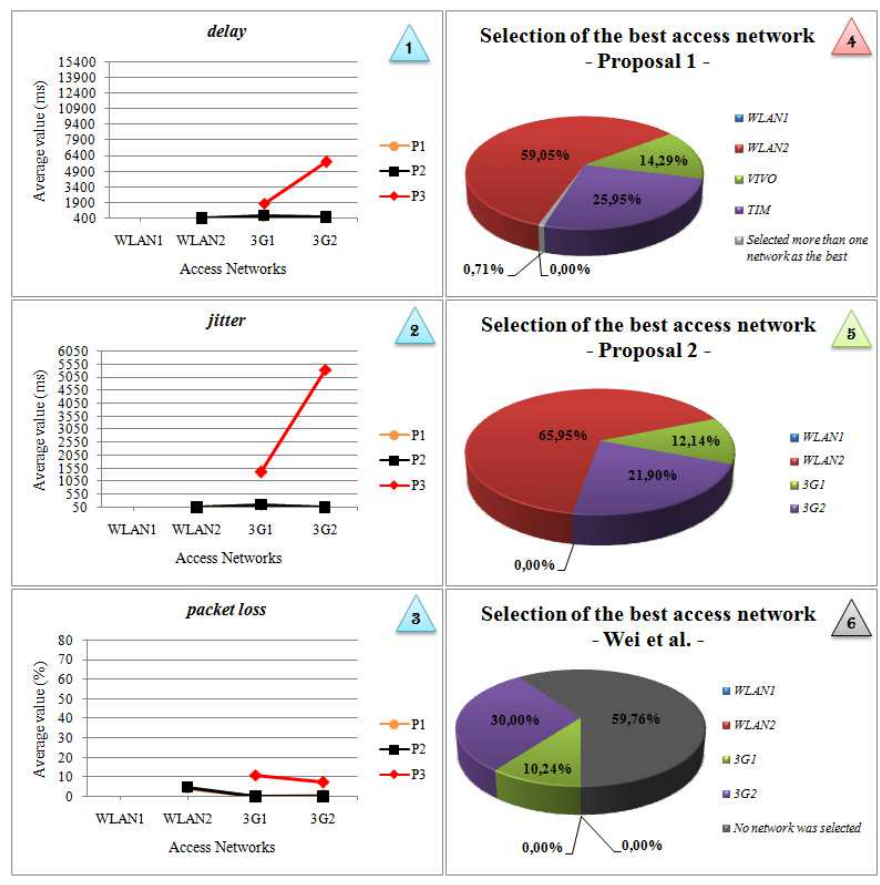

Figure 14. Competing traffic in the WLAN1 network.

As it can be seen in chart 5, the WLAN2 network has obtained $65.95 \%$ of choice, averaging its delay network parameters around $400 \mathrm{~ms}$, jitter around $50 \mathrm{~ms}$ and packet loss around $4 \%$. The $3 \mathrm{G} 1$ network has obtained $12.14 \%$ of choice, averaging its delay network parameter around $400 \mathrm{~ms}$, jitter around $190 \mathrm{~ms}$ and packet loss around $0 \%$. And finally, the 3G2 network has obtained $21.90 \%$ of choice, averaging its delay network parameter around $400 \mathrm{~ms}$, jitter around $50 \mathrm{~ms}$ and packet loss around $0 \%$. It may be observed that because the WLAN1 network parameters are above the audio traffic parameters considered as good or great, it was not selected in any of the iterations.

In the first proposal, represented by chart 4 , there is $0.71 \%$ of choice in the selection of more than one access network, which is considered a problem, since the handover has to happen for the best network selected. The WLAN2 network has obtained $59.05 \%$ of choice, averaging its delay network parameter around $400 \mathrm{~ms}$, jitter around $50 \mathrm{~ms}$ and packet loss around $4 \%$. The $3 \mathrm{G} 1$ network has obtained $14.29 \%$ of choice, averaging its delay network parameter around $400 \mathrm{~ms}$, jitter around $190 \mathrm{~ms}$ and packet loss around $0 \%$. And finally, the $3 \mathrm{G} 2$ network has obtained $25.95 \%$ of choice, averaging its delay network parameter around $400 \mathrm{~ms}$, jitter around $50 \mathrm{~ms}$ and packet loss around $0 \%$.

The authors' proposal in [7], represented by chart 6 , has not selected any network in $59.76 \%$ of total iterations, because in addition to the criterion of packet loss that can have a value of 0 , the monetary cost criterion has a value of 0 real in the WLAN1 and WLAN2 networks. The 3G1 network has obtained $10.24 \%$ of choice, averaging its delay network parameter around $1900 \mathrm{~ms}$, jitter around $1550 \mathrm{~ms}$ and packet loss around $10 \%$. The 3G2 network has got $30 \%$ of choice, averaging its delay network parameter around $6400 \mathrm{~ms}$, jitter around 5550ms and packet loss around $8 \%$. 
High competing traffic in the WLAN2 network

Figure 15 shows that proposals 2 and 3 , charts 5 and 6 respectively, have succeeded in obtaining great performance in selecting the best access network, within the given characteristics.

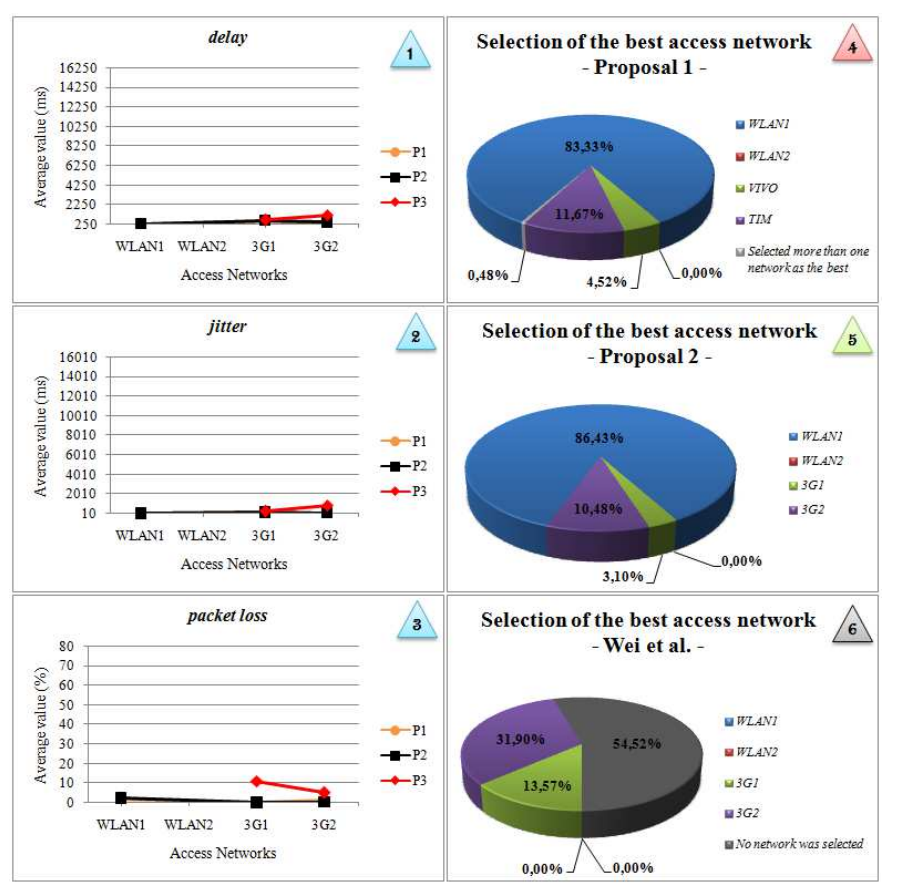

Figure 15. Competing traffic in WLAN2 network.

As it can be seen in chart 5, the WLAN1 network has got $86.43 \%$ of choice, averaging its delay network parameter around $250 \mathrm{~ms}$, jitter around $10 \mathrm{~ms}$ and packet loss around $2 \%$. The $3 \mathrm{G} 1$ network has obtained $3.10 \%$ of choice, averaging its delay network parameter around $260 \mathrm{~ms}$, jitter around $10 \mathrm{~ms}$ and packet loss around $0 \%$. And finally, the 3G2 network has obtained $10.48 \%$ of choice, averaging its delay network parameter around $250 \mathrm{~ms}$, jitter around $10 \mathrm{~ms}$ and packet loss around $0 \%$. It may be observed that because the WLAN2 network parameters are above the audio traffic parameters considered as good or great, it was not selected in any of the iterations.

In the fourth graph representing the first proposal, there is $0.48 \%$ of choice in the selection of more than one access network, which is a problem, since the handover has to happen for the best network selected. The WLAN1 network has got $83.33 \%$ of choice, averaging its delay network parameter around $250 \mathrm{~ms}$, jitter around $10 \mathrm{~ms}$ and packet loss around $2 \%$. The $3 \mathrm{G} 1$ network has obtained $4.52 \%$ of choice, averaging its delay network parameter around $260 \mathrm{~ms}$, jitter around $10 \mathrm{~ms}$ and packet loss around $0 \%$. And finally, the $3 \mathrm{G} 2$ network has obtained $11.67 \%$ of choice, averaging its delay network parameter around $250 \mathrm{~ms}$, jitter around $10 \mathrm{~ms}$ and packet loss around $0 \%$.

The authors' proposal in [7], represented by chart 6 , has not selected any network in $54.52 \%$ of total iterations, because in addition to the criterion of packet loss that can have a value of 0 , the monetary cost criterion has a value of 0 real in WLAN1 and WLAN2 networks. The 3G1 network has obtained $13.57 \%$ of choice, averaging its delay network parameter around $250 \mathrm{~ms}$, jitter around $10 \mathrm{~ms}$ and packet loss around $10 \%$. The 3G2 network has obtained $31.90 \%$ of choice, averaging its delay network parameter around $300 \mathrm{~ms}$, jitter around $15 \mathrm{~ms}$ and packet loss around $7 \%$.

\section{High competing traffic in WLAN1 and WLAN2 networks}

Figure 16 shows that the second proposal, chart 5, has performed well in selecting the best access network when compared to the first proposal, but a little worse than the third proposal.

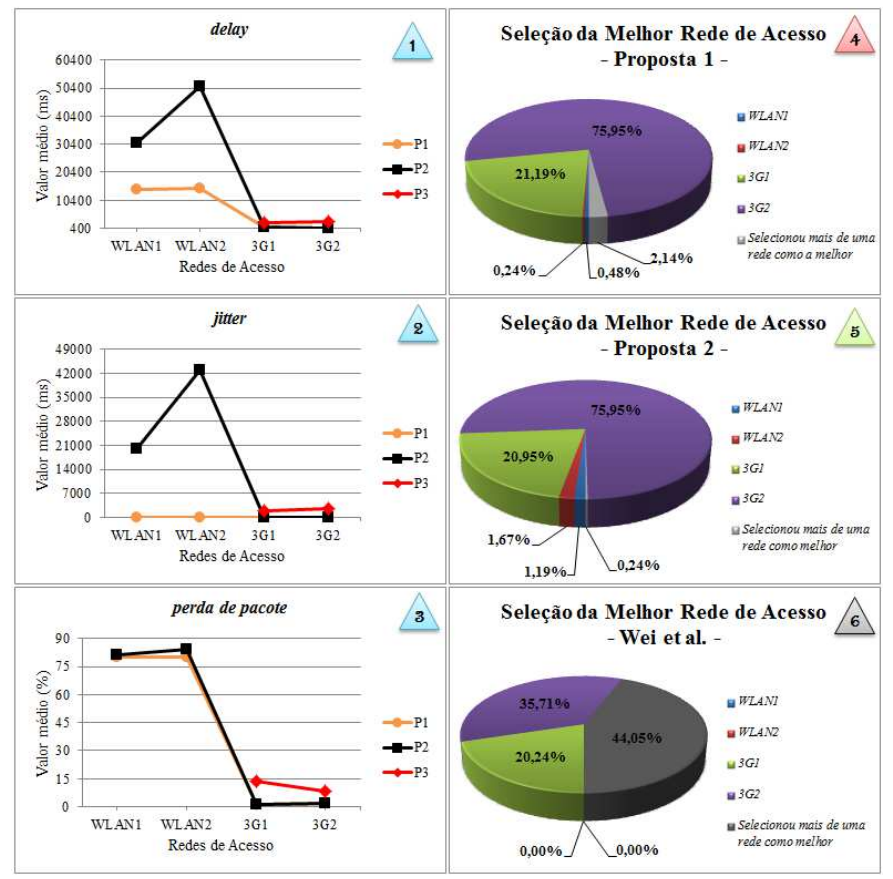

Figure 16. Competing traffic in the WLAN1 and WLAN2 networks

As it can be seen in chart 5 , there is $0.24 \%$ of choice in the selection of more than one access network, which is a problem, since the handover has to happen for the best network selected. The WLAN1 network has got $1.19 \%$ of choice, averaging its delay network parameter around $30400 \mathrm{~ms}$, jitter around $21000 \mathrm{~ms}$ and packet loss around $80 \%$. The WLAN2 network has obtained $1.67 \%$ of choice, averaging its delay network parameter around 50400ms, jitter around $42000 \mathrm{~ms}$ and packet loss around $80 \%$. The $3 \mathrm{G} 1$ network has obtained $20.95 \%$ of choice, averaging its delay network parameter around $400 \mathrm{~ms}$, jitter around $10 \mathrm{~ms}$ and packet loss around $0 \%$. And finally, the 3G2 network has obtained $75.95 \%$ of choice, averaging its delay network parameter around $400 \mathrm{~ms}$, jitter around $10 \mathrm{~ms}$ and packet loss around $2 \%$.

In the first proposal, represented by chart 4 , there is $2.14 \%$ of choice in the selection of more than one access network, which is considered a problem, since the handover has to happen for the best network selected. The WLAN1 network has obtained $0.48 \%$ of choice, averaging its delay network parameter around $15400 \mathrm{~ms}$, jitter around $10 \mathrm{~ms}$ and packet loss 
around $80 \%$. The WLAN2 network has obtained $0.24 \%$ of choice, averaging its delay network parameter around $15400 \mathrm{~ms}$, jitter around $10 \mathrm{~ms}$ and packet loss around $80 \%$. The $3 \mathrm{G} 1$ network has obtained $20.95 \%$ of choice, averaging its delay network parameter around $400 \mathrm{~ms}$, jitter around $10 \mathrm{~ms}$ and packet loss around 0\%. And finally, the 3G2 network has obtained $75.95 \%$ of choice, averaging its delay network parameter around $400 \mathrm{~ms}$, jitter around $10 \mathrm{~ms}$ and packet loss around $2 \%$.

The authors' proposal in [7], represented by chart 6, has not selected any network in $44.05 \%$ of total iterations, because in addition to the criterion of packet loss that can have a value of 0 , the monetary cost criterion has a value of 0 real in the WLAN1 and WLAN2 networks. The 3G1 network has obtained $20.24 \%$ of choice, averaging its delay network parameter around $400 \mathrm{~ms}$, jitter around $10 \mathrm{~ms}$ and packet loss around $14 \%$. The $3 \mathrm{G} 2$ network has obtained $35.71 \%$ of choice, averaging its delay network parameter around 400ms, jitter around $15 \mathrm{~ms}$ and packet loss around $12 \%$.

\section{Result of the experiments with mobility}

To obtain the results presented in this scenario a set of 358 collection iterations of the network variables was considered during the 50 drives/shifts from the access point to the edge and vice versa.

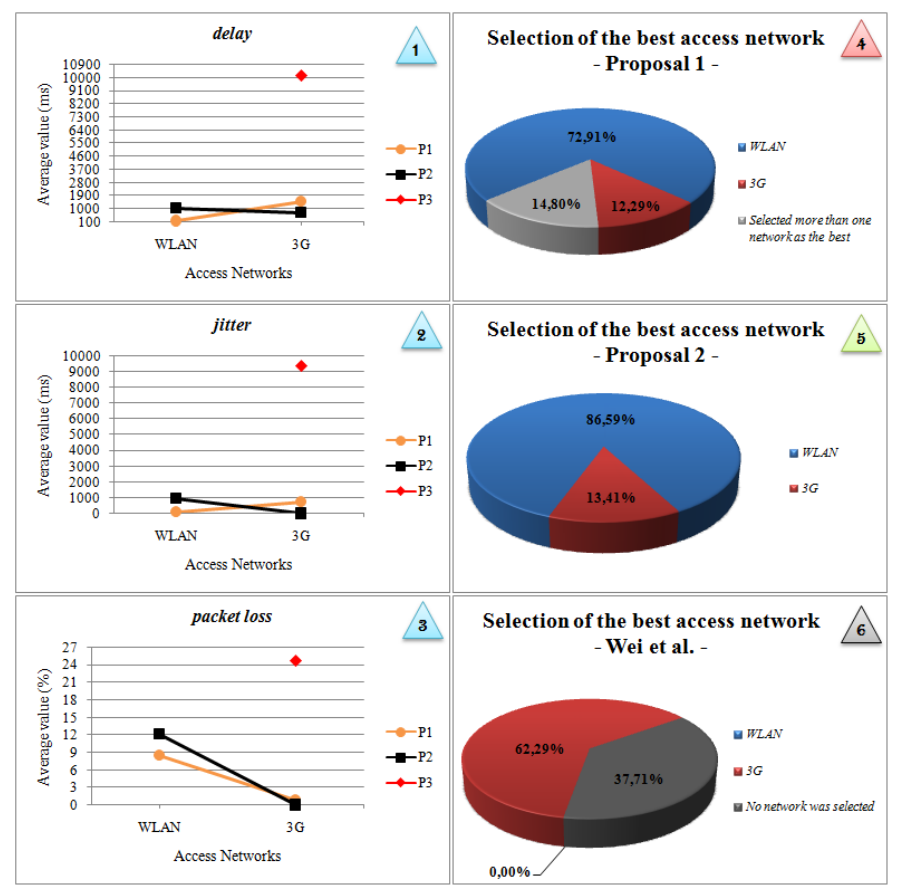

Figure 17. Traffic in the environment with mobility.

As it can be seen in chart 5, the WLAN network has obtained $86.59 \%$ of choice, averaging its delay network parameter around $1000 \mathrm{~ms}$, jitter around $1000 \mathrm{~ms}$ and packet loss around $12 \%$. The $3 \mathrm{G}$ network has obtained $13.41 \%$ of choice, averaging its delay network parameter around $900 \mathrm{~ms}$, jitter around $10 \mathrm{~ms}$ and packet loss around $0 \%$. Although the $3 \mathrm{G}$ network parameters are smaller than the WLAN network, the monetary cost parameter in the WLAN is 0 real and in the $3 \mathrm{G}$ network 89.90 reais, leading to a preference for the WLAN network.

In the first proposal, chart 4 , there is $14.80 \%$ of choice in the selection of more than one access network, which is considered a problem, since the handover has to happen for the best network selected. The WLAN network has obtained $72.91 \%$ of choice, averaging its delay network parameter around $100 \mathrm{~ms}$, jitter around $10 \mathrm{~ms}$ and packet loss around $8 \%$. The $3 \mathrm{G}$ network has got $12.29 \%$ of choice, averaging its delay network parameter around $1700 \mathrm{~ms}$, jitter around $900 \mathrm{~ms}$ and packet loss around $1 \%$.

The authors' proposal in [7], represented by chart 6, has not selected any network in $44.05 \%$ of total iterations, because in addition to the criterion of packet loss that can have a value of 0 , the monetary cost criterion has a value of 0 real in WLAN network. The $3 \mathrm{G}$ network has obtained $62.29 \%$ of choice, averaging its delay network parameter around $10000 \mathrm{~ms}$, jitter around $9500 \mathrm{~ms}$ and packet loss around $25 \%$.

\section{CONCLUSIONS AND FUTURE WORK}

The network selection is a very important step, or even the most important, in the handover process, since it will make every effort in implementing the handover so that the terminal can connect to the selected network through decision-making techniques that best meet the user's access point preferences.

Therefore, we can see that the decision-making methods are useful in sorting alternatives in order to achieve a goal, and together with an artificial intelligence technique, the result becomes even more accurate.

As future work, we intend to integrate these proposals with handover software by encompassing the whole process of mobility management.

\section{REFERENCES}

[1] Kassar, M., Kervella, B., and Pujolle, G. An overview of vertical handover decision strategies in heterogeneous wireless networks. Computer Communications, 31(10):2607-2620, 2008.

[2] Singhrova, A. and Prakash, N. Adaptive Vertical Handoff Decision Algorithm forWireless Heterogeneous Networks. In Proceedings of the 2009 11th IEEE International Conference on High Performance Computing and Communications, volume 0, pages 476-481. IEEE Computer Society, 2009.

[3] Ciccarese, G., De Blasi, M., Marra, P., Mighali, V., Palazzo, C., Patrono, L., and Stefanizzi, M. Vertical handover algorithm for heterogeneous wireless networks. In 2009 Fifth International Joint Conference on INC, IMS and IDC, pages 1948-1954, 2009.

[4] Stevens-Navarro, E. and Wong, V. Comparison between vertical handoff decision algorithms for heterogeneous wireless networks. In Vehicular Technology Conference, volume 2, pages 947-951, 2006.

[5] Godor, G. and Detari, G. Novel network selection algorithm for various wireless network interfaces. In Mobile and Wireless Communications Summit, 2007. 16th IST, pages 1-5, 2007.

[6] Alkhawlani, M. and Ayesh, A. Access network selection based on fuzzy logic and genetic algorithms. Advances in Artificial Intelligence, 8(1):1-12, 2008.

[7] Wei, Y., Hu, Y., and Song, J. Network selection strategy in heterogeneous multi-access environment. The Journal of China Universities of Posts and Telecommunications, 14:16-49, 2007.

[8] Kurose, J. and Ross, K. Redes de Computadores e a Internet: uma abordagem top-down. 5. ed. - São Paulo: Addison Wesley, 2010.

[9] ITU-T, R. G. 114. One-way transmission time, 18, 2000. 
[10] Silva, D. J. Análise de qualidade de serviço em redes corporativas. Dissertação de Mestrado, Instituto de Computação, Universidade Estadual de Campinas (UNICAMP), 2004.

[11] Tran, P. and Boukhatem, N. Comparison of madm decision algorithms for interface selection in heterogeneous wireless networks. In Software, Telecommunications and Computer Networks, 2008. SoftCOM 2008. 16th International Conference on, pages 119-124, 2008.

[12] Radhika, K.; Reddy, A. V. Network selection in heterogeneous wireless networks based on fuzzy multiple criteria decision making. International Journal of Computer Applications, Foundation of Computer Science (FCS), v. 22, n. 1, p. 7-10, 2011.

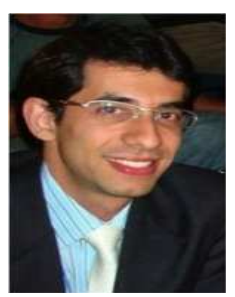

Vinícius Rios is assistant professor at the University of Tocantins (UNITINS) in distance education mode and face. He is Graduated in Information Systems from the Lutheran University of Brazil (ULBRA) (2005), specialization in Management and Consulting in Telecommunications from the Brazilian Institute of Postgraduate Studies and Extension (IBPEX) (2006) and Master's degree in Electrical Engineering from the University of Brasilia (UNB) (2012). He has experience in Information Systems with emphasis in Computer Networking, Operating Systems, Wi-Fi Networks, Mobility Management and Artificial Intelligence.

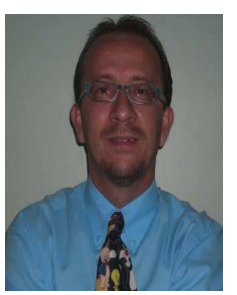

Claudio Monteiro is a full professor at the Federal Institute of Education, Science and Technology of Tocantins, Computing Science Department, Palmas TO, ACM member and leader of the Research Group on Networks Computers (GREDES - gredes.ifto.edu.br). $\mathrm{He}$ graduated in data processing technology from the University of Amazonia (1990) and Masters in Computer Science from Federal University of Paraíba (1997) and Ph.D. in Electrical Engineering from the University of Brasilia - UNB (2012). Actualy, has been developed a framework for reduce the latency of the handover between heterogeneous wireless networks. In addition, a. He has experience in computer science, with emphasis on wireless networks, network protocols, QoS/QoE and operating systems.

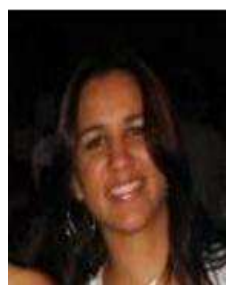

Vanice Cunha was born in Brasília, Federal District (Brazil) on august 24, 1984. She became Master degree in Electrical Engineering from the University of Brasilia in 2012. Her research project involved QoV (Quality of Video) and QoS (Quality of Service) in wireless networks of 3rd Generation. Currently she is a female teacher at the Instituto Federal de Brasilia. 